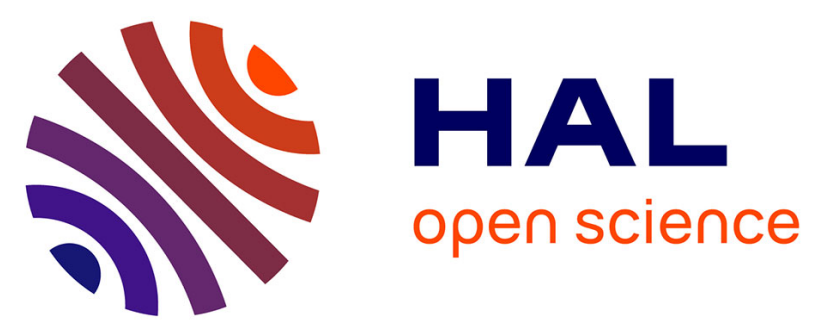

\title{
In vitro compressive properties of skeletal muscles and inverse finite element analysis: comparison of human versus animals
}

Fuhao Mo, Zhefen Zheng, Haotian Zhang, Guibing Li, Zurong Yang, Deyi Sun

\section{- To cite this version:}

Fuhao Mo, Zhefen Zheng, Haotian Zhang, Guibing Li, Zurong Yang, et al.. In vitro compressive properties of skeletal muscles and inverse finite element analysis: comparison of human versus animals. Journal of Biomechanics, 2020, 109, pp.109916. 10.1016/j.jbiomech.2020.109916 . hal-03230539

\section{HAL Id: hal-03230539 \\ https://hal-amu.archives-ouvertes.fr/hal-03230539}

Submitted on 20 May 2021

HAL is a multi-disciplinary open access archive for the deposit and dissemination of scientific research documents, whether they are published or not. The documents may come from teaching and research institutions in France or abroad, or from public or private research centers.
L'archive ouverte pluridisciplinaire HAL, est destinée au dépôt et à la diffusion de documents scientifiques de niveau recherche, publiés ou non, émanant des établissements d'enseignement et de recherche français ou étrangers, des laboratoires publics ou privés.

\section{(ㅇ)(1) $\$$}

Distributed under a Creative Commons Attribution - NonCommercial - NoDerivatives 44.0 


\section{In vitro compressive properties of skeletal muscles and inverse finite element analysis: comparison of human versus animals}

Fuhao MO ${ }^{1,3}$, Zhefen ZHENG ${ }^{1}$, Haotian ZHANG ${ }^{1}$, Guibing LI ${ }^{4}$, Zurong YANG ${ }^{5}$, Deyi $\operatorname{Sun}^{2 *}$

${ }^{1}$ State Key Laboratory of Advanced Design and Manufacture for Vehicle Body, Hunan University, Changsha, Hunan, 410082, China

${ }^{2}$ Department of Orthopedics, The Second Xiangya Hospital of Central South University, 139 Renmin Road, Changsha, Hunan, 410011, China

${ }^{3}$ Aix-Marseille University, IFSTTAR, LBA UMRT24, Marseille, France

${ }^{4}$ School of Mechanical Engineering, Hunan University of Science and Technology, Xiangtan 411201, China

${ }^{5}$ Department of Ultrasound, The Second Xiangya Hospital, Central South University, 139 Renmin Road, Changsha, Hunan 410011, China

1 Abstract: Virtual finite element human body models have been widely used in 2 biomedical engineering, traffic safety injury analysis, etc. Soft tissue modeling like 3 skeletal muscle accounts for a large portion of a human body model establishment, and 4 its modeling method is not enough explored. The present study aims to investigate the 5 compressive properties of skeletal muscles due to different species, loading rates and fiber orientations, in order to obtain available parameters of specific material laws as

7 references for building or improving the human body model concerning both modeling accuracy and computational cost. A series of compressive experiments of skeletal

9 muscles were implemented for human gastrocnemius muscle, bovine and porcine hind leg muscle. To avoid long-time preservation effects, all experimental tests were carried 
out in 24 hours after that the samples were harvested. Considering computational cost and generally used in the previous human body models, one-order hyperelastic Ogden model and three-term simplified viscoelastic quasi-linear viscoelastic (QLV) were selected for numerical analysis. Inverse finite element analysis was employed to obtain corresponding material parameters. With good fitting records, the simulation results presented available material parameters for human body model establishment, and also indicated significant differences of muscle compressive properties due to species, loading rates and fiber orientations. When considering one-order Ogden law, it is worthy of noting that the inversed material parameters of the porcine muscles are similar to those of the human gastrocnemius regardless of fiber orientations. In conclusion, the obtained material parameters in the present study can be references for global human body and body segment modeling.

Keywords: Skeletal muscle, Human gastrocnemius, Inverse analysis, Finite element simulation, Parameter identification 


\section{Introduction}

Finite element (FE) Human body models (HBMs) are widely used for biomechanical analysis in biomedical engineering, transport safety, sport science, and other human involved activities (Florio, 2018; Halloran, et al., 2010; Hedenstierna, et al., 2008; Lenhart, et al., 2015). Skeletal muscle accounts for about $40 \%$ of the body mass, therefore an understanding of its mechanical properties is important for virtual human body modeling and related biomechanical application (Chomentowski et al.,2011, Takaza, et al., 2013). Muscle tissues can be roughly characterized to be highly nonlinear, viscoelastic, anisotropic and strain rate dependency like most biological tissues, while their properties can also vary significantly due to diversity of species. Thus, the experimental test and numerical modeling of muscle tissues are challenging works.

Skeletal muscle is composed of about $70-80 \%$ water, $3 \%$ fat and $10 \%$ collagen (Vignos and Lefkowitz, 1959). As it is very soft, most of the previous studies often tested it in compression setups. Partly due to experimental condition limitation, many previous studies primarily investigated mechanical behaviors of skeletal muscles in compression with different animal species, and obtained corresponding parameters with inverse analysis. For example, several previous studies (McElhaney, 1966; Van Loocke et al., 2006, 2008; Sligtenhorst and Cronin, 2006; Song et al., 2007; Chawla et al., 2009) investigated high strain rate effects of compression loading on skeletal muscles till 3700/s, while other studies presented experimental results with relatively lower strain rates till 0.001/s (Sacks, 2000; Sligtenhorst et al., 2006; Song et al., 2007; Xu et al., 2011). With regard to fiber orientations, continuous researches were implemented with different animal muscles primarily considering the fiber orientations of $0^{\circ}, 45^{\circ}$ and $90^{\circ}$ (Bosboom et al., 2001 a, b; Van Loocke et al., 2006; Böl et al., 2012; Mohammadkhah et al., 2016). Although the uniform macro feature of experimental curves can be noted for different animal muscles, the mechanical properties in detail during compression change a lot due to the species as well as experimental conditions. Thus, the limitations 
of these animal muscle experiments for FE human body modeling have always existed.

To our knowledge, previous researchers on human skeletal muscle properties under compression loading were not enough and often limited to cadaver specimens with long-time preservation. Vannah et al. (1996) conducted quasi-static compression experiments of human muscles to provide design data for lower limb prostheses and other soft tissue supporting devices. Dhaliwal et al. (2002) conducted low energy impact tests on human cadaver muscles and obtained corresponding dynamic compressive mechanical properties. These previous studies primarily used the samples harvested from cadavers without indicating details of preservation conditions, like preservation time. However, the previous investigations have indicated that long term formalin preservation can significantly change mechanical properties of biological tissues, even for bone tissues (Kikugawa et al., 2004; Ohman et al., 2008; Zhang et al., 2019). Hence, we believe that implementing the experiments with short time preservation samples should be more available for soft tissues like skeletal muscle.

Hence, the objective of the present study was to investigate the compressive properties of human skeletal muscles with short term preservation less than 24 hours and compare them with those of other animals, in order to provide available modeling parameters for FE human modeling or related biomechanical application. In addition, many virtual FE human body or body segment models with skeletal muscle modeling were developed in the previous studies for various considerations, where the Ogden or QLV laws were usually used for these complicated model establishment (Mo et al., 2019). Here, we believe that in a FE human body modeling both accuracy and calculating efficiency should be considered for engineering application. Thus, two generally used material types for the global human body or segment models were selected to obtain specific material parameters by inverse finite element analysis in order to use them in existing or future FE human body models. 


\section{Materials and methods}

\subsection{Sample preparation and experimental procedure}

All experiments were approved by the ethics committee of the Second Xiangya Hospital of Central South University (NO. 2012-S231) and the informed consent was obtained from the patients participating in the study. Cubic muscle samples with a characteristic edge length of $10 \mathrm{~mm}$ were obtained from human gastrocnemius muscle as well as bovine and porcine hind legs. Summary of sample sizes is listed in Table 1. The bovine samples were harvested from the hindquarter of a large Yorkashire, and the porcine samples were harvested from the hindquarter of a Chinese yellow cattle. The human gastrocnemius muscle was obtained from two amputee donators (age $69 \pm 3$ years old) without any leg muscle disorders or diseases. The tissues were fixed using formalin to prevent tissue dissolution for no more than 24 hours before the experiments.

Before the experiment, the skin, fat and fascia were firstly removed from the muscle tissues to obtain standard cubic testing specimens. All operations were carried out by a surgeon through a scalpel and an assistive block with ruler to control the size. Subsequent compressive experiments were performed using different loading rates and along different fiber orientations $\left(0^{\circ}, 45^{\circ}\right.$ and $\left.90^{\circ}\right)$ as shown in Fig. 1. The MTS E45 electronic universal testing machine was used to compress the specimens up to $50 \%$ strain at rates of $0.05 \% / \mathrm{s}, 0.5 \% / \mathrm{s}$ and $5 \% / \mathrm{s}$. The measurement range of the selected force sensor is $30 \mathrm{kN}$ with a resolution of $0.001 \mathrm{~N}$. As pre-compression may lead to unpredictable permanent tissue deformation, each specimen was tested once and no precondition was applied to the specimen. At least three successful specimen tests were achieved at each testing condition. A total of successful 99 compression experiments were conducted at different loading rates and fiber directions.

Fig.1. Schematic of compression experiments with different loading rates and fiber directions 
Table 1. Sample size and average specimen dimensions at different fiber orientations

\begin{tabular}{|c|c|c|c|c|c|}
\hline Specimen & Fiber direction & $\begin{array}{l}\text { Average height } \\
\pm \text { std }(\mathrm{mm})\end{array}$ & $\begin{array}{l}\text { Average width } \\
\pm \mathrm{std}(\mathrm{mm})\end{array}$ & $\begin{array}{c}\text { Average } \\
\text { thickness } \\
\pm \text { std }(\mathrm{mm})\end{array}$ & $\begin{array}{c}\text { Sample size } \\
\text { (N) }\end{array}$ \\
\hline \multirow{3}{*}{ Bovine } & $0^{\circ}$ & $10.5 \pm 0.6$ & $10.7 \pm 0.5$ & $10.5 \pm 0.6$ & 12 \\
\hline & $45^{\circ}$ & $10.8 \pm 1.2$ & $11.1 \pm 1.2$ & $10.6 \pm 0.6$ & 12 \\
\hline & $90^{\circ}$ & $10.9 \pm 0.9$ & $10.8 \pm 0.7$ & $10.8 \pm 0.7$ & 12 \\
\hline \multirow{3}{*}{ Porcine } & $0^{\circ}$ & $11.3 \pm 0.9$ & $10.8 \pm 0.8$ & $10.9 \pm 0.9$ & 12 \\
\hline & $45^{\circ}$ & $11.1 \pm 1.4$ & $10.5 \pm 1.1$ & $10.5 \pm 0.5$ & 12 \\
\hline & $90^{\circ}$ & $11.7 \pm 0.8$ & $11.3 \pm 0.9$ & $10.8 \pm 0.7$ & 12 \\
\hline \multirow{3}{*}{ Human } & $0^{\circ}$ & $10.0 \pm 1.0$ & $10.7 \pm 0.5$ & $10.3 \pm 0.5$ & 9 \\
\hline & $45^{\circ}$ & $9.9 \pm 0.9$ & $10.4 \pm 0.8$ & $10.1 \pm 0.7$ & 9 \\
\hline & $90^{\circ}$ & $12.0 \pm 2.1$ & $10.6 \pm 1.9$ & $10.3 \pm 0.9$ & 9 \\
\hline
\end{tabular}

\subsection{Mathematical modeling}

111 Following the previous studies (Comley et al. 2012, Takaza et al. 2013, Mo et al, 2018, 2019a, b), one-order Ogden hyperelastic material law and three-terms quasi-linear

113 viscoelastic (QLV) material law were usually selected for modeling passive behavior 114 of muscle tissues in human body models. The Ogden hyperelastic material law is expressed as follows,

$$
W=\sum_{i=1}^{n} \frac{\mu_{i}}{\alpha_{i}}\left(\lambda_{1}^{\alpha_{i}}+\lambda_{2}^{\alpha_{i}}+\lambda_{3}^{\alpha_{i}}-3\right)+K(J-1-\ln J)
$$

117 Where $W$ is the strain energy of the model; $\mu$ is the initial shear modulus, $\alpha$ is the 118 deviatoric exponent, $\lambda_{i}$ is the deviatoric principal stretches in three directions: $\mathrm{x}, \mathrm{y}$ and $119 \mathrm{z} ; J$ represents the bulk modulus. The skeletal muscle was considered incompressible, 120 thus, $J$ equaled to 1 . Therefore, the simple one-order Ogden law is expressed as follows,

$$
W=\frac{2 \mu}{\alpha^{2}}\left(\lambda_{1}^{\alpha}+\lambda_{2}^{\alpha}+\lambda_{3}^{\alpha}-3\right)
$$


122 The viscoelastic QLV law is expressed as equation (3) and (4),

$$
\sigma(t)=\int_{0}^{t} G(t-\tau) \frac{\partial \sigma^{e}(\lambda)}{\partial \lambda} \cdot \frac{\partial \lambda}{\partial \tau} d \tau
$$

Where $\partial \sigma^{e}(\lambda) / \partial \lambda$ is the instantaneous elastic response, $\partial \lambda / \partial \tau$ is the stretch history; $G(t-\tau)$ is the relaxation function.

Based on the QLV law, we used a simplified model focusing on instantaneous elastic response in compression. And three terms of model coefficients were adopted. The equation is expressed as follows,

$$
\sigma_{\varepsilon}(\varepsilon)=C_{1} \varepsilon^{1}+C_{2} \varepsilon^{2}+C_{3} \varepsilon^{3}
$$

Where $C_{1}, C_{2}$ and $C_{3}$ are the coefficients of instantaneous elastic responses; $\varepsilon^{1}, \varepsilon^{2}$ and $\varepsilon^{3}$ are the principal strains in three directions.

\subsection{Inverse analysis}

Inverse analysis has been applied for defining material parameters of soft tissues (Ahn, et al., 2010; Chawla, et al., 2009; Böl, et al., 2012; Nava, et al., 2008; Samur, et al., $2005,2007)$. The purpose of the inverse analysis was to minimize the error between the experimental results and simulation responses by using an optimization algorithm to identify optimal material parameters (Böl, et al., 2012). The agreement between experimental results and simulation results were evaluated by the objective function as follows,

$$
f(x)=\sqrt{\frac{\sum_{i}^{n}\left(F_{i}^{\exp }-F_{i}^{F E M}\right)^{2}}{n}}
$$

Where $F_{i}^{e x p}$ is the experimental force value, $F_{i}^{F E M}$ is the responsive force of finite element simulation, and $n$ is the number of data points. The process of inverse analysis for material parameter identification is described in the following section. 


\subsection{Identification of material parameters}

145 To identify material parameters of the tested skeletal muscles, a method combing

146

147 inverse solve and finite element optimization of material parameters were employed, as shown in Fig. 2. The errors between the simulation and experimental results are calculated by equation (5). A custom python program using a least-squares algorithm was firstly used to fit experimental results to acquire initial parameters of the corresponding laws. Then, their values were optimized and finally determined by inversed finite element analysis. Adaptive response surface method (ARSM) was adopted in the FE simulations to minimize the error and obtain optimal parameters until calculation convergence referring to the previous study (Wang et al.,2007), which is a direct optimization method based on response surface. The basic idea of ARSM method is to construct a response surface with fewer sample points first and determine the optimization direction. During the optimization process, new design points are obtained along the gradient direction of the response surface, and introduced into the design space so that the response surface model can be gradually updated to improve optimization efficiency and fitting accuracy. By optimizing and updating the response surface, the optimal solution can be continuously approached to the real optimal solution.

\section{Fig.2. Schematic illustration of material parameter identification}

The FE simulations were implemented with Ls-Dyna codes. The specimen was meshed with hexahedral solid elements of the size $1 \mathrm{~mm}$ by Hypermesh software. Element quality was checked to avoid distorted elements and to satisfy the minimum time step criteria. The time step was set as $1.0 \mathrm{e}-5$. Surface to surface contacts were defined between the platens and the specimen, and a self-contact of the specimen was defined to avoid solid collapse during large deformation. The lower platen was constrained with no freedom in all directions, while the upper platen can freely translate along the compression direction. The friction coefficient between the platen and specimen was set as 0.3 according to the previous study (Wu, et al., 2004). 


\section{Results}

173

174

175

176

177

\subsection{Experimental results}

Characteristic compressive stress-strain responses are classified based on tissue fiber orientations, compression strain rates and species (Fig. 3-Fig. 5). The bovine and porcine muscle properties are illustrated in Fig. 3 and Fig. 4, respectively. Compressive responses of the human gastrocnemius muscles are shown in Fig. 5. As general soft biological tissues, the experimental data of the muscle tissues scatter on a large scale in the present study. When comparing compressive responses of different species as shown in Fig. 6, the substantial difference can be noted due to species, fiber orientations and strain rates. The compressive properties of the porcine muscles seem to be closer to the human gastrocnemius muscles than those of the bovine muscles.

In most testing conditions except for $90^{\circ}$ bovine muscle, potential strain effects are noted in the testing range from $0.05 \%$ to $5 \%$ for all species and fiber orientations, while the Cauchy stress value inclines significantly with the increasing strain rate at $50 \%$ strain as shown in Fig. $6(\mathrm{p}<0.005)$. With the increase of the strain rate, the scattering range of the compressive curves in most of testing conditions tends to enlarge. The stiffest tissue response was obtained when the muscle fibers were oriented in perpendicular to the loading direction ( $90^{\circ}$ fiber orientation), followed by a fiber orientation of $45^{\circ}$. Fiber orientation of $0^{\circ}$ in parallel with the loading direction yielded the softest response.
(a) $0^{\circ}$ (b) $45^{\circ}$ (c) $90^{\circ}$

Fig.3. Compressive stress-stretch responses of the bovine muscles at various rates and fiber orientations

(a) $0^{\circ}$ (b) $45^{\circ}$ (c) $90^{\circ}$

Fig.4. Compressive stress-stretch responses of the porcine muscles at various rates and fiber 
(a) $0^{\circ}$ (b) $45^{\circ}$ (c) $90^{\circ}$

200

Fig.5. Compressive stress-stretch responses of the human gastrocnemius muscles at various rates and fiber orientations

Fig.6. Comparison of compressive responses of different species under a strain level of $50 \%$

\subsection{Identification of material parameters}

We used the averaged experimental curves of different fiber orientations and different species as the objective curves for the optimization of material parameters. Through the above-mentioned method, the typical fitting results of numerical simulations to experimental results considering the human skeletal muscles of three fiber orientations are shown in Fig. 7. All simulation results are in good agreement with the experimental responses.

Inversed material parameters of different muscle tissues using one-order Ogden law were illustrated in Table 2. The corresponding material parameters of three-terms simplified QLV law were listed in Table 3. For both material laws, the obtained material parameters for different species and fiber orientations present some differences. Although significant differences $(\mathrm{p}<0.05)$ of material parameters existed between the porcine and human muscles considering different fiber orientations, the inversed material parameters of the averaged curves of all three fiber orientations show similar values for both human $(\mu=3.43 \mathrm{kPa}, \alpha=8.74)$ and porcine $(\mu=3.63 \mathrm{kPa}, \alpha=8.74)$ muscles concerning one-order Ogden law.
(a) $0^{\circ}$ (b) $45^{\circ}$ (c) $90^{\circ}$

Fig.7. Typical fitting results of the finite element simulations to the experimental results of the human skeletal muscles. (2) 
Table 2 Optimized muscle material parameters of one-order Ogden law

\begin{tabular}{cccccc}
\hline Species & Fiber orientation & Material parameters & $\mathrm{R}^{2}(\mathrm{FE})$ & RMSE \\
\hline \multirow{3}{*}{ Bovine } & $0^{\circ}$ & $\mu=0.26 \mathrm{kPa}$ & $\alpha=14.00$ & 0.994 & 1.21 \\
& $45^{\circ}$ & $\mu=0.65 \mathrm{kPa}$ & $\alpha=13.83$ & 0.998 & 1.67 \\
& $90^{\circ}$ & $\mu=2.00 \mathrm{kPa}$ & $\alpha=10.11$ & 0.997 & 8.91 \\
& Average & $\mu=1.18 \mathrm{kPa}$ & $\alpha=11.97$ & 0.998 & 2.12 \\
\hline \multirow{3}{*}{ Porcine } & $0^{\circ}$ & $\mu=0.54 \mathrm{kPa}$ & $\alpha=14.00$ & 0.983 & 11.07 \\
& $45^{\circ}$ & $\mu=3.80 \mathrm{kPa}$ & $\alpha=9.00$ & 0.969 & 115.50 \\
& $90^{\circ}$ & $\mu=3.96 \mathrm{kPa}$ & $\alpha=8.92$ & 0.994 & 23.08 \\
& Average & $\mu=3.63 \mathrm{kPa}$ & $\alpha=8.74$ & 0.983 & 40.59 \\
\hline $0^{\circ}$ & $\mu=2.24 \mathrm{kPa}$ & $\alpha=8.97$ & 0.989 & 15.72 \\
& $45^{\circ}$ & $\mu=3.77 \mathrm{kPa}$ & $\alpha=9.00$ & 0.982 & 63.88 \\
& $90^{\circ}$ & $\mu=5.07 \mathrm{kPa}$ & $\alpha=9.14$ & 0.994 & 43.79 \\
& Average & $\mu=3.43 \mathrm{kPa}$ & $\alpha=8.74$ & 0.934 & 173.33 \\
\hline
\end{tabular}

Table 3 Optimized muscle material parameters of three-terms QLV law

\begin{tabular}{ccccc}
\hline Species & Fiber orientation & Material parameters & $\mathrm{R}^{2}(\mathrm{FE})$ & $\mathrm{RMSE}$ \\
\hline \multirow{3}{*}{ Bovine } & $0^{\circ}$ & $\mathrm{C} 1=88.61 \mathrm{C} 2=-772.05 \mathrm{C} 3=1716.00$ & 0.937 & 18.74 \\
& $45^{\circ}$ & $\mathrm{C} 1=169.70 \mathrm{C} 2=-1500.86 \mathrm{C} 3=3607.17$ & 0.957 & 45.73 \\
& $90^{\circ}$ & $\mathrm{C} 1=132.00 \mathrm{C} 2=-1140.00 \mathrm{C} 3=3320.00$ & 0.960 & 79.09 \\
& Average & $\mathrm{C} 1=122.18 \mathrm{C} 2=-1065.46 \mathrm{C} 3=2808 . .00$ & 0.978 & 26.77 \\
\hline \multirow{3}{*}{ Porcine } & $0^{\circ}$ & $\mathrm{C} 1=90.00 \mathrm{C} 2=-1088.22 \mathrm{C} 3=2849.00$ & 0.977 & 22.26 \\
& $45^{\circ}$ & $\mathrm{C} 1=99.00 \mathrm{C} 2=-994.16 \mathrm{C} 3=3366.99$ & 0.992 & 22.51 \\
& $90^{\circ}$ & $\mathrm{C} 1=189.00 \mathrm{C} 2=-1477.87 \mathrm{C} 3=4488.00$ & 0.991 & 36.25 \\
& Average & $\mathrm{C} 1=132.00 \mathrm{C} 2=-990.00 \mathrm{C} 3=2981.00$ & 0.982 & 40.32 \\
\hline Human & $0^{\circ}$ & $\mathrm{C} 1=115.36 \mathrm{C} 2=-965.06 \mathrm{C} 3=2758.01$ & 0.967 & 42.45
\end{tabular}




$\begin{array}{cccc}45^{\circ} & \mathrm{C} 1=165.00 \mathrm{C} 2=-1160.00 \mathrm{C} 3=3310.00 & 0.964 & 76.57 \\ 90^{\circ} & \mathrm{C} 1=436.05 \mathrm{C} 2=-3124.03 \mathrm{C} 3=7616.21 & 0.941 & 367.21 \\ \text { average } & \mathrm{C} 1=253.00 \mathrm{C} 2=-1810.00 \mathrm{C} 3=4590.00 & 0.945 & 152.51\end{array}$

228

229

230

231

232

Notes: RMSE represents Root Mean Squared Error.

\section{Discussion}

Although some previous studies have investigated skeletal muscle properties in different loading types using different animal specimens (Mohammadkhah et al.,2016, Nie et al.,2011, Simms et al.,2012, Takaza et al.,2013a), the experimental results of human skeletal muscles especially the data with short preservation time in formalin or in status were rare. In the present study, we aim to provide material properties for human body modeling, especially in the application of comfort and impact analysis during seating and car crash. In these two loading conditions, human body muscles generally experience a compression loading. In addition, when we compared the published muscle properties of different animals (Song et al., 2007, Dhaliwal et al., 200, Mohammadkhah et al.,2016, Van Sligtenhorst et al.,2006, Takaza et al.,2014), substantial differences of mechanical behaviors in compression can be noted. Hence, the first purpose of this study was to investigate compressive behaviors of human skeletal muscle without long formalin storing time, then obtain their material parameters of generally used and computationally efficient material laws for the improvement or establishment of human body models. By the way, the dominant fiber directions can be different considering anatomic structures of different muscles. Muscle compressive properties from three representative fiber directions were measured and analyzed. Compressive properties of muscle tissues in other fiber directions should be located between them. In the establishment of a related human body model, we recommended either establishing or employing an anisotropic constitutive material law in the model, or optimizing the corresponding muscle parameters of the available isotropic laws considering fiber distribution and boundary loading conditions. 
The Cauchy stress-strain relationship presented in this study provided a reference for investigating mechanical behaviors of human skeletal muscles. The results showed that the Cauchy stress during compression increased with the increasing strain rate, which was similar to the previous researches (Chawla, et al., 2009; Sligtenhorst, et al., 2006; Song, et al., 2007; Van Loocke, et al., 2006; Van Loocke, et al., 2008). The Cauchy stress of $50 \%$ compression strain at the compression loading rate of $5 \% / \mathrm{s}$ was about 3 times larger than that at the compression rate of $0.05 \% / \mathrm{s}$, which was qualitatively similar to the results at other strain rates (Van Loocke, et al., 2006; Van Loocke, et al., 2008). The cross-fiber orientation mechanical response was found to be stiffer than other fiber orientations, which was similar to the findings of the previous researches with different loading strain rates (Song, et al., 2007; Böl, et al., 2012).

As the inversed material parameters shown in Table 2, the optimized shear modulus $\mu$ of $5.07 \mathrm{kPa}$ for human gastrocnemius was close to in vivo experimental results using supersonic shear wave elastography (SWE) of Maïsetti et al. (2012) study or the results of our verifying measurements. This can indicate the reliability of our results, and that the obtained tissue properties are close to in vivo muscle tissue properties. In addition, the average inversed material parameters of one-order Ogden law regardless of fiber orientations for the porcine and human muscles are similar. But those of the bovine muscle are largely different with them. To some extent, it could indicate that using porcine muscle for experimental tests could provide more useful information for human muscle tissue modeling if the human tissue experiment is limited. But it can be also influenced by native species' difference. To extend experimental possibility, we believe that it is important to find proper alternative animal tissues with similar mechanical properties to human tissues for experimental researches.

The present study selected one-order Ogden law for skeletal muscle modeling, as it is a simple and reasonable solution for soft tissue modeling. Especially concerning its 
application in a global biomechanical model, the high computational efficiency was extremely appreciated in our previous foot model and lower limb modeling (Mo et al., 2018, 2019). We compared the computational cost of one-order Ogden law and threeterms simplified QLV law in the present compression modeling using Ls-Dyna solver. With 8-core $\mathrm{Xeon}{ }^{\circledR} \mathrm{CPU}$, the calculation time for a simple compression simulation is 23 min and 27mins, respectively. The one-order Ogden law has some advantages in saving computational cost as well as controlling the stability of a global human body model for loading conditions without large concerns on viscoelasticity. Considering a global human body or large body segment modeling, we believe the balance of modeling accuracy and computational cost should be achieved properly with regard to research objectives.

The present study combined experimental tests and inverse analysis method to investigate the effects of loading rate, fiber orientation and species differences on compressive behaviors of skeletal muscles. A large number of experiments and numerical simulations were implemented, and available material parameters were obtained for human body modeling reference. There are still several limitations. First, the limited sample size for each testing condition may partly limit part of the robustness of our results. As limited pure muscle tissues can be obtained after removing other fiber tissues in one donator, we had to harvest samples from two amputees not as we can obtain all muscle samples from one animal. But if we enlarge our sample size, the effects of individuals' difference would be also extended. Second, we use an ideal and standard geometry for inverse finite element analysis to obtain muscle material parameters. As indicated by the previous study (Böl et al, 2012), to further precisely define the muscle parameters, an inverse finite element method with detailed geometry definition could be more powerful. Additionally, we also believe that using short-time preservation tissues for experiments or adopting in-vivo measuring methods like the SWE method for obtaining or evaluating material parameters can be further investigated for virtual FE human model establishment. 


\section{Conclusion}

311

312

313

Inspired by the objective of human body modeling, the present study investigated the compressive properties of skeletal muscles with different species, loading rates and fiber orientations. Two commonly used material laws of Ogden and QLV constitutive models were selected and simplified for numerical analysis in the consideration of computational efficiency and modeling accuracy. Optimized material parameters were well obtained through inverse analysis based on custom-made codes and optimal finite element simulations, which can be available references for human body modeling. The experimental results show substantial differences between species, loading rates and fiber orientations. Referring to the material parameters of one-order Ogden law, similar values between the porcine muscles and the human gastrocnemius were found regardless of fiber orientations. The inversed shear modulus was further verified by in vivo SWE measurement, thus it also indicated that the present parameters can reflect the properties of in vivo human gastrocnemius muscle. Coupling experimental and simulation investigations on different human muscles could be extended in the future to further evaluate the present method and findings.

\section{Conflict of interest statement}

The authors assert that there are no conflicts of interest of any type.

\section{Acknowledgments}

This study was supported by the National Key Research and Development Program of China (2018YFC1105800), National Natural Science Foundation of China (Grant No. 51875187, 51621004), and Hunan Province Science and Technology Plan (Grant No. 2019JJ40021). We also thank gratefully to Dr. Tang Liu's and Dr. Pengcheng Dou's help for experimental tests. 


\section{Reference}

1. Ahn, B., and J. Kim. 2010. Measurement and characterization of soft tissue behavior with surface deformation and force response under large deformations $[\mathrm{J}]$. Med. Image. Anal. 14(2):138-148, 2010.

2. Böl, M., R. Kruse, A. E. Ehret, K. 2012. Leichsenring, and T. Siebert. Compressive properties of passive skeletal muscle-The impact of precise sample geometry on parameter identification in inverse finite element analysis [J]. J. Biomech. 45(15):2673-2679.

3. Bosboom, E. M. H., M. K. C. Hesselink, C. W. J. Oomens, C. V. C. Bouten, M. R. Drost, and F. P. T. Baaijens. 2001. Passive transverse mechanical properties of skeletal muscle under in vivo compression [J]. J. Biomech. 34(10):1365-1368.

4. Bosboom, E. M. H., J. A. M. Thomassen, C. W. J. Oomens, C. V. C. Bouten, and F. P. T. Baaijens. 2001. A numerical-experimental approach to determine the transverse mechanical properties of skeletal muscle [C], J. Middleton, M.L. Jones, N.G. Shrive(Eds.), Computer Methods In Biomechanics And Biomedical Engineering, 3, Gordon and Breach Sciences Publishers, Ne York, pp. 187-192.

5. Chawla, A., S. Mukherjee, and B. Karthikeyan. 2009. Characterization of human passive muscles for impact loads using genetic algorithm and inverse finite element methods [J]. Biomech. Model. Mechan. 8(1):67-76, 2009.

6. Chomentowski, P., P. M. Coen, Z. Radikova, B. H. Goodpaster, and F. G. S. Toledo. 2011. Skeletal Muscle Mitochondria in Insulin Resistance: Differences in Intermyofibrillar Versus Subsarcolemmal Subpopulations and Relationship to Metabolic Flexibility [J]. J. Clin. Endocrinol. Metab. 96(2):494-503.

7. Comley, K., and N. Fleck. 2012. The compressive response of porcine adipose tissue from low to high strain rate [J]. Int. J. Impact. Eng. 46:1-10.

8. Dhaliwal, T. S., P. Beillas, C. C. Chou, P. Prasad, K. H. Yang, and A. I. King. 2002. 
Structural response of lower leg muscles in compression: a low impact energy study employing volunteers, cadavers and the hybrid III [J]. Stapp. Car . Crash. J. 46:229243.

9. Florio, C. S. 2018. Effectiveness of various isometric exercises at improving bone strength in cortical regions prone to distal tibial stress fractures [J]. Int. J. Numer Method. Biomed. Eng. 34(6): e2976.

10. Halloran, J. P., M. Ackermann, A. Erdemir, and A. J. van den Bogert. 2010. Concurrent musculoskeletal dynamics and finite element analysis predicts altered gait patterns to reduce foot tissue loading [J]. J. Biomech. 43(14):2810-2815.

11. Hedenstierna, S., P. Halldin, and K. Brolin. 2008. Evaluation of a combination of continuum and truss finite elements in a model of passive and active muscle tissue [J]. Comput. Methods. Biomech. Biomed. Eng. 11(6):627-639.

12. Kikugawa, H., and T. Asaka. 2004. Effect of long-term formalin preservation on bending properties and fracture toughness of bovine compact bone [J]. Mater. Trans. 45(10):3060-3064.

13. Lenhart, R. L., J. Kaiser, C. R. Smith, and D. G. Thelen. 2015. Prediction and Validation of Load-Dependent Behavior of the Tibiofemoral and Patellofemoral Joints During Movement [J]. Ann. Biomed. Eng. 43(11):2675-2685.

14. Maisetti, O., F. Hug, K. Bouillard, and A. Nordez. 2012. Characterization of passive elastic properties of the human medial gastrocnemius muscle belly using supersonic shear imaging [J]. J. Biomech. 45(6):978-984.

15. McElhaney, J. H. 1966. Dynamic response of bone and muscle tissue [J]. J. Appl. Physiol. 21(4):1231-1236.

16. Mo, F., F. Li, M. Behr, Z. Xiao, G. Zhang, and X. Du. 2018. A Lower Limb-Pelvis Finite Element Model with 3D Active Muscles [J]. Ann. Biomed. Eng. 46(1):86-96.

17. Mo, F., J. Li, M. Dan, T. Liu, and M. Behr. 2019. Implementation of controlling 
strategy in a biomechanical lower limb model with active muscles for coupling multibody dynamics and finite element analysis [J]. J. Biomech. 91:51-60.

18. Mo, F., J. Li, Z. Yang, S. Zhou, and M. Behr. 2019. In Vivo Measurement of Plantar Tissue Characteristics and Its Indication for Foot Modeling [J]. Ann. Biomed. Eng. 47: 2356-2371.

19. Mohammadkhah, M., P. Murphy, and C. K. Simms. 2016. The in vitro passive elastic response of chicken pectoralis muscle to applied tensile and compressive deformation [J]. J. Mech. Behav. Biomed. Mater. 62:468-480.

20. Nava, A., E. Mazza, M. Furrer, P. Villiger, and W. H. Reinhart. 2018. In vivo mechanical characterization of human liver [J]. Med. Image. Anal. 12(2):203-216.

21. Nie, X., J.-I. Cheng, W. W. Chen, and T. Weerasooriya. 2011. Dynamic Tensile Response of Porcine Muscle [J]. J. Appl. Mech. Mar 2011, 78(2): 021009-14.

22. Ohman, C., E. Dall'Ara, M. Baleani, S. V. S. Jan, and M. Viceconti. 2008. The effects of embalming using a $4 \%$ formalin solution on the compressive mechanical properties of human cortical bone [J]. Clin. Biomech. 23(10):1294-1298.

23. Sacks, M. S. 2000. Biaxial mechanical evaluation of planar biological materials [J]. J. Elast. 61(1-3):199-246.

24. Samur, E., M. Sedef, C. Basdogan, L. Avtan, and O. Duzgun. 2005. A robotic indenter for minimally invasive characterization of soft tissues [C], in CARS 2005: Computer Assisted Radiology and Surgery, edited by H. U. Lemke, K. Inamura, K. Doi, M. W. Vannier, and A. G. Farman, 713-718.

25. Samur, E., M. Sedef, C. Basdogan, L. Avtan, and O. Duzgun. 2007. A robotic indenter for minimally invasive measurement and characterization of soft tissue response [J]. Med. Image. Anal. 11(4):361-373.

26. Simms, K.C., Van Loocke, M., Lyons, C.G., 2012. Skeletal muscle in compression:modelling approaches for the passive muscle bulk [J]. Int. J. 
Multiscale. Com. 10 (2), 143 - 154.

27. Song, B., W. Chen, Y. Ge, and T. Weerasooriya. 2007. Dynamic and quasi-static compressive response of porcine muscle [J]. J. Biomech. 40(13):2999-3005.

28. Takaza, M., Cooney, G.M., Mcmanus, G., Stafford, P., Simms, C.K.,2014. Assessing the microstructural response to applied deformation in porcine passive skeletal muscle.[J]. J. Mech. Behav. Biomed. Mater. 40: 115-126.

29. Takaza, M., Moerman, K.M., Gindre, J., Lyons, G., Simms, C.K.,2013a. The anisotropic mechanical behaviour of passive skeletal muscle tissue subjected to large tensile strain.[J]. J. Mech. Behav. Biomed. Mater. 17: 209-220.

30. Takaza, M., K. M. Moerman, and C. K. Simms. 2013. Passive skeletal muscle response to impact loading: Experimental testing and inverse modelling [J]. J. Mech. Behav. Biomed. Mater. 27:214-225.

31. Van Loocke, M., C. G. Lyons, and C. K. Simms. 2006. A validated model of passive muscle in compression [J]. J. Biomech. 39(16):2999-3009.

32. Van Loocke, M., C. G. Lyons, and C. K. Simms. 2008. Viscoelastic properties of passive skeletal muscle in compression: Stress-relaxation behaviour and constitutive modelling [J]. J. Biomech. 41(7):1555-1566.

33. Van Sligtenhorst, C., D. S. Cronin, and G. W. Brodland. 2006. High strain rate compressive properties of bovine muscle tissue determined using a split Hopkinson bar apparatus [J]. J. Biomech. 39(10):1852-1858.

34. Vannah, W. M., and D. S. Childress. 1996. Indentor tests and finite element modeling of bulk muscular tissue in vivo [J]. J. Rehabil. Res. Dev. 33(3):239-252.

35. Vignos, P. J., Jr., and M. Lefkowitz. 1959. A biochemical study of certain skeletal muscle constituents in human progressive muscular dystrophy [J]. J. Clin. Invest. $38(6): 873-881$

36. Wang, H., G. Li and Z. Zhong. 2008. Optimization of sheet metal forming processes 
by adaptive response surface based on intelligent sampling method [J]. J. Mater. Process. Tech. 197(1-3), 77-88.

37. Wu, J. Z., R. G. Dong, and A. W. Schopper. 2004. Analysis of effects of friction on the deformation behavior of soft tissues in unconfined compression tests $[\mathrm{J}]$. J. Biomech. 37(1):147-155.

38. Zhang, G., S. Wang, S. Xu, F. Guan, Z. Bai, and H. Mao. 2019. The Effect of Formalin Preservation Time and Temperature on the Material Properties of Bovine Femoral Cortical Bone Tissue [J]. Ann. Biomed. Eng. 47(4):937-952. 


\section{Figure legends}

Figure 1. Schematic of compression experiments with different loading rates and fiber directions.

Figure 2. Schematic illustration of material parameter identification.

Figure 3. Compressive stress-stretch responses of the bovine muscles at various rates and fiber orientations. (a) $0^{\circ}$ (b) $45^{\circ}$ (c) $90^{\circ}$

Figure 4. Compressive stress-stretch responses of the porcine muscles at various rates and fiber orientations. (a) $0^{\circ}$ (b) $45^{\circ}$ (c) $90^{\circ}$

Figure 5. Compressive stress-stretch responses of the human gastrocnemius muscles at various rates and fiber orientations. (a) $0^{\circ}$ (b) $45^{\circ}$ (c) $90^{\circ}$

Figure 6. Comparison of compressive responses of different species under a strain level of $50 \%$.

Figure 7. Typical fitting results of the finite element simulations to the experimental results of the human skeletal muscles. (a) $0^{\circ}$ (b) $45^{\circ}$ (c) $90^{\circ}$ 

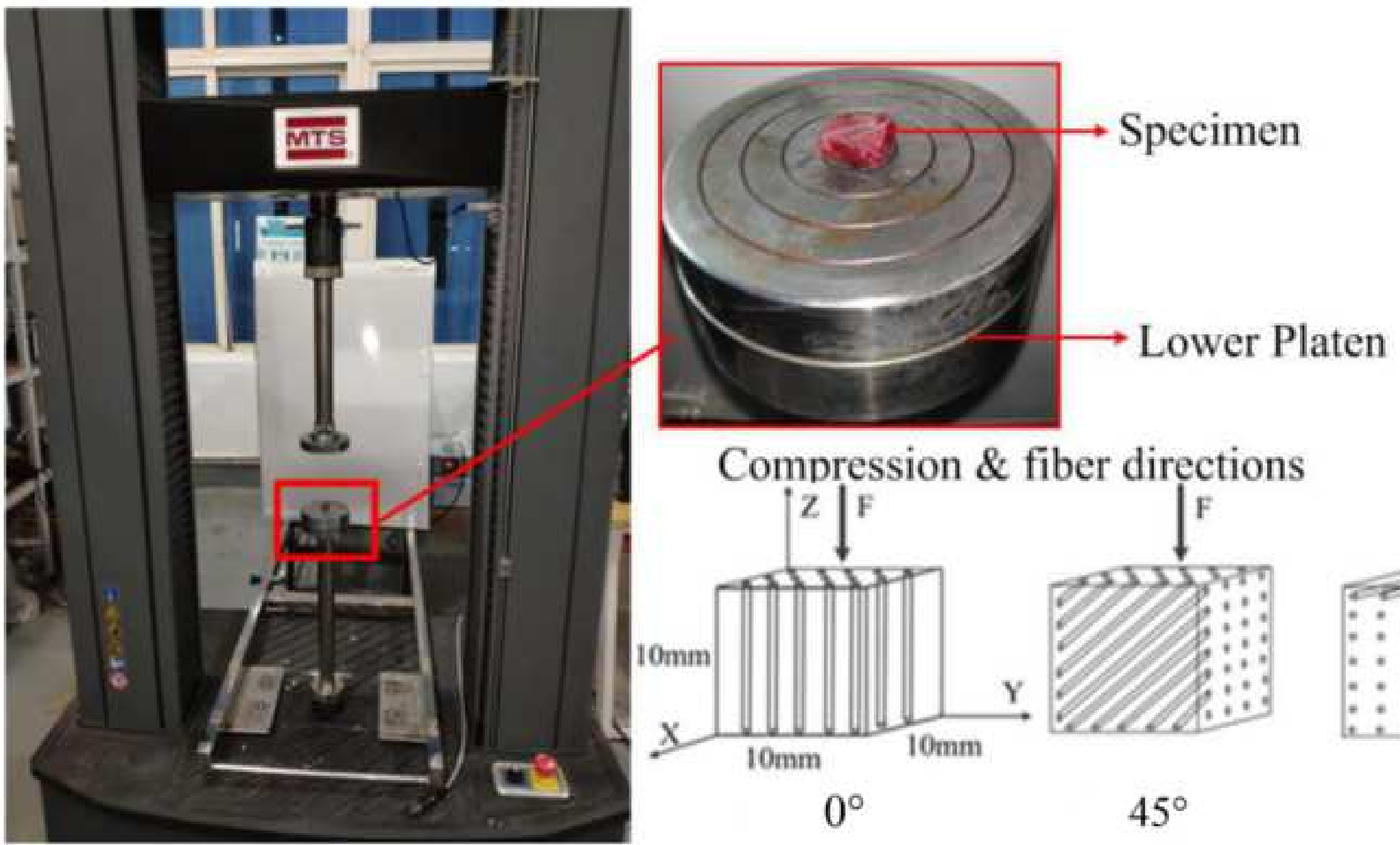

Compression \& fiber directions

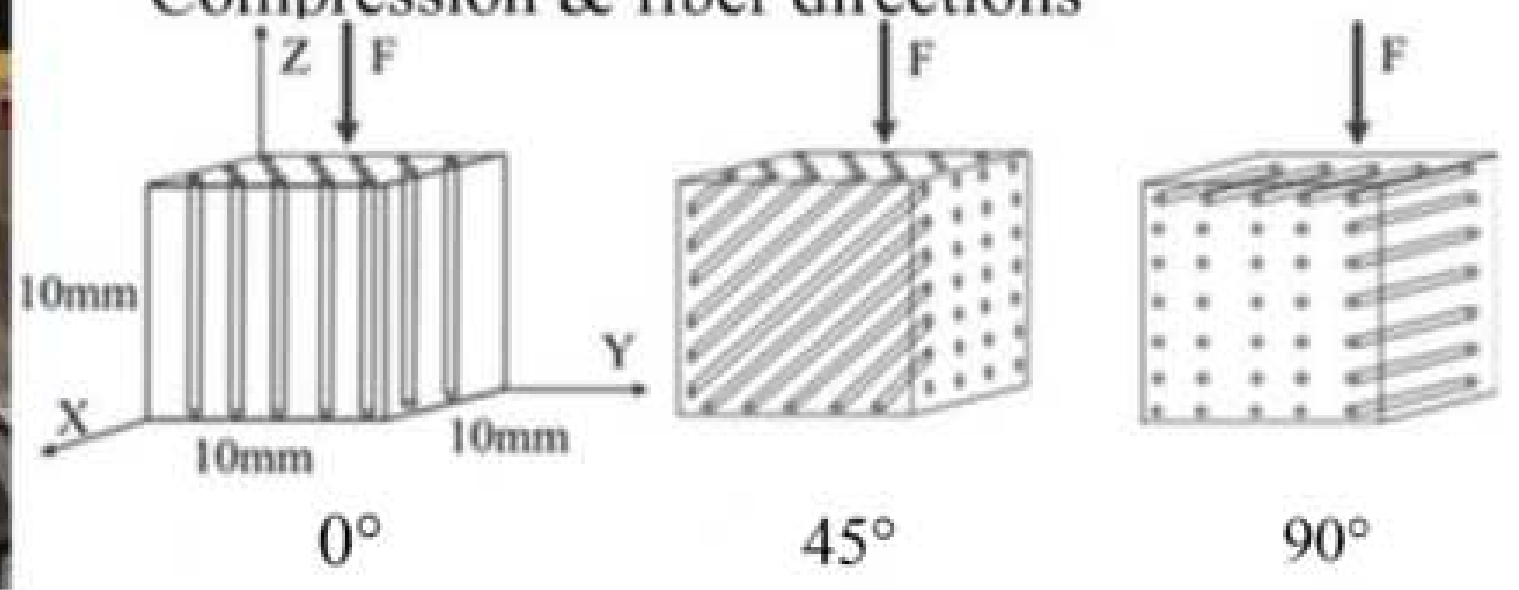




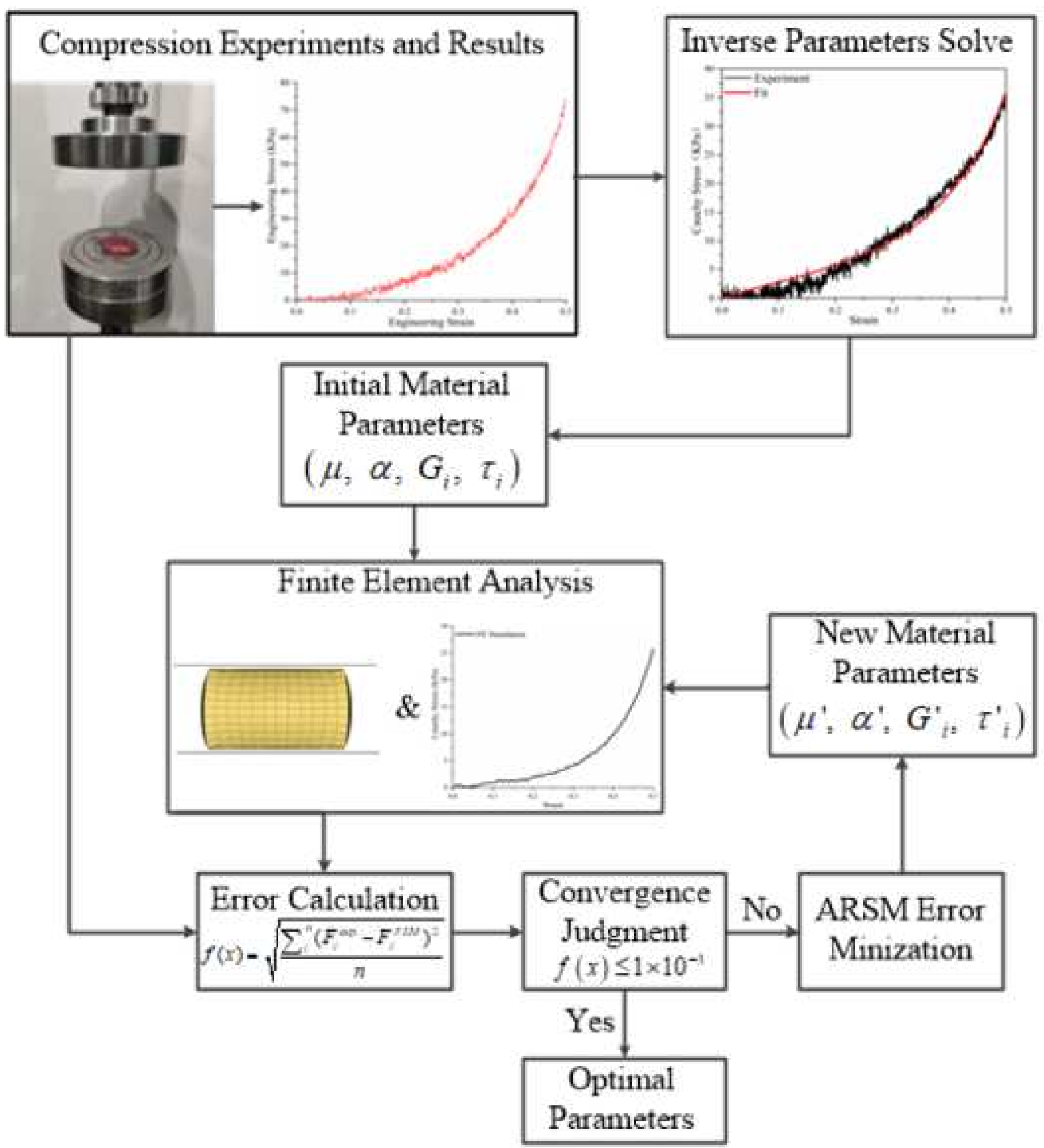


Click here to access/download;Figure;Figure.3(a).png $\underline{\underline{ \pm}}$

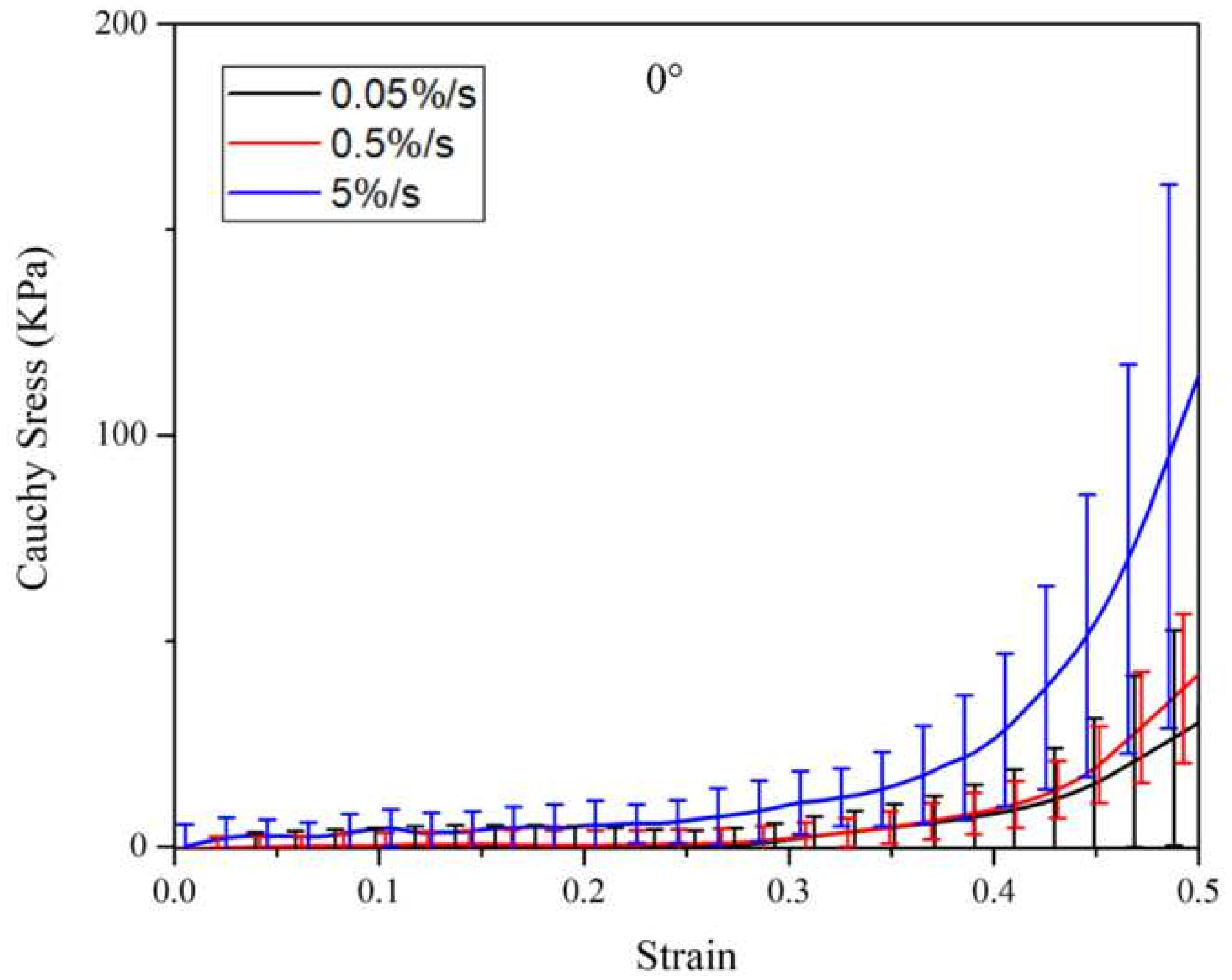


Click here to access/download;Figure;Figure.3(b).png $\underline{\underline{ \pm}}$

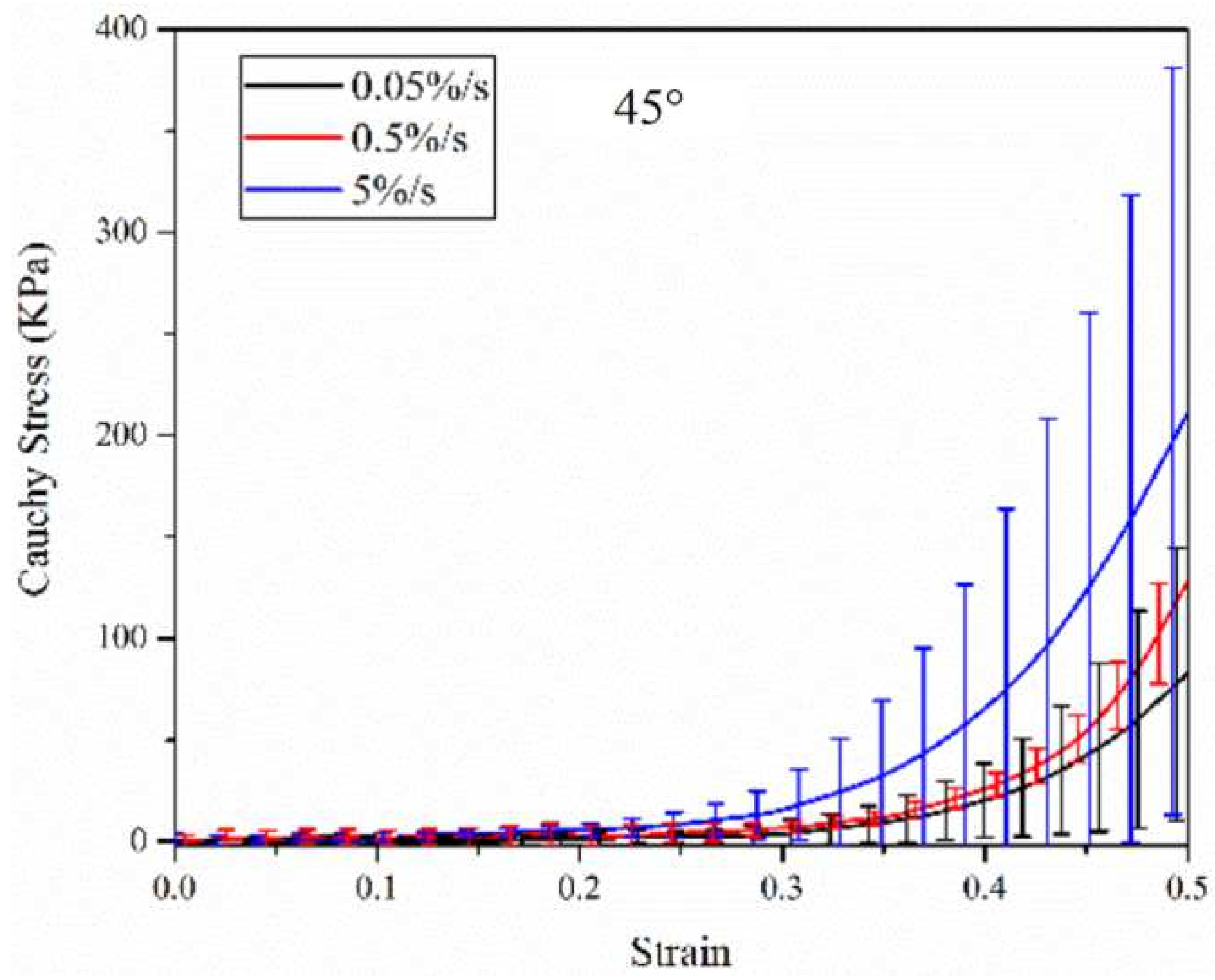


Click here to access/download;Figure;Figure.3(c).png $\underline{\underline{ \pm}}$

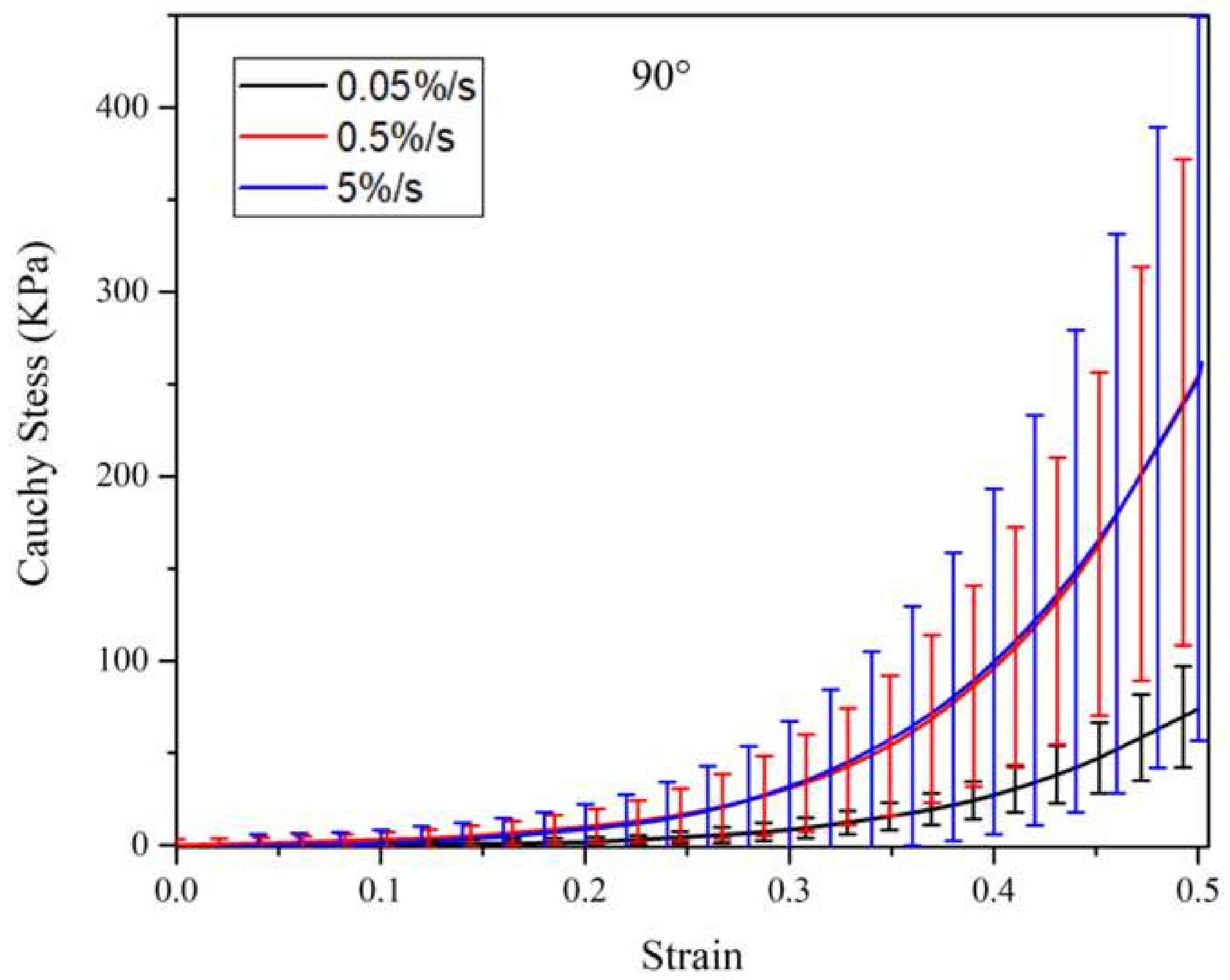




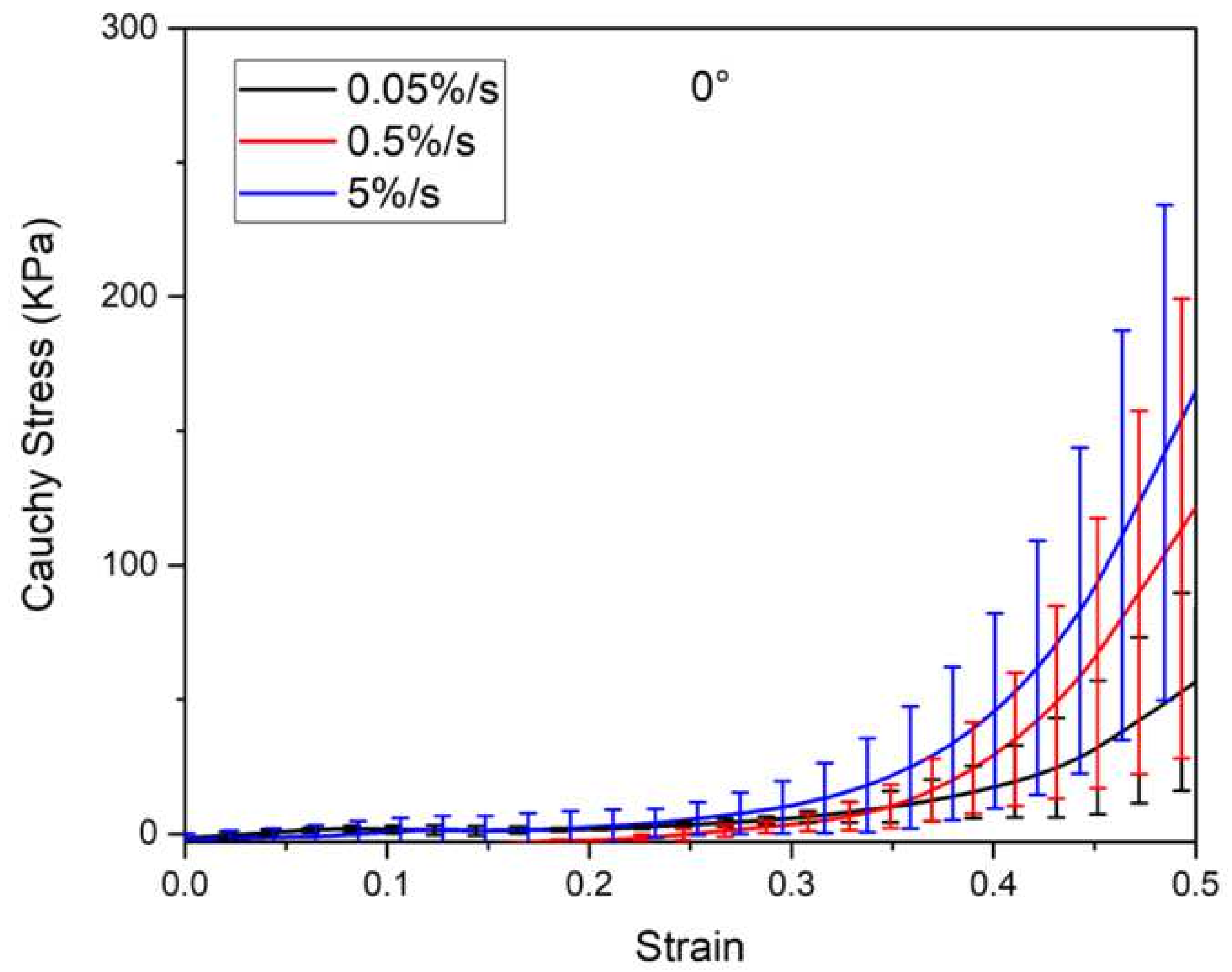




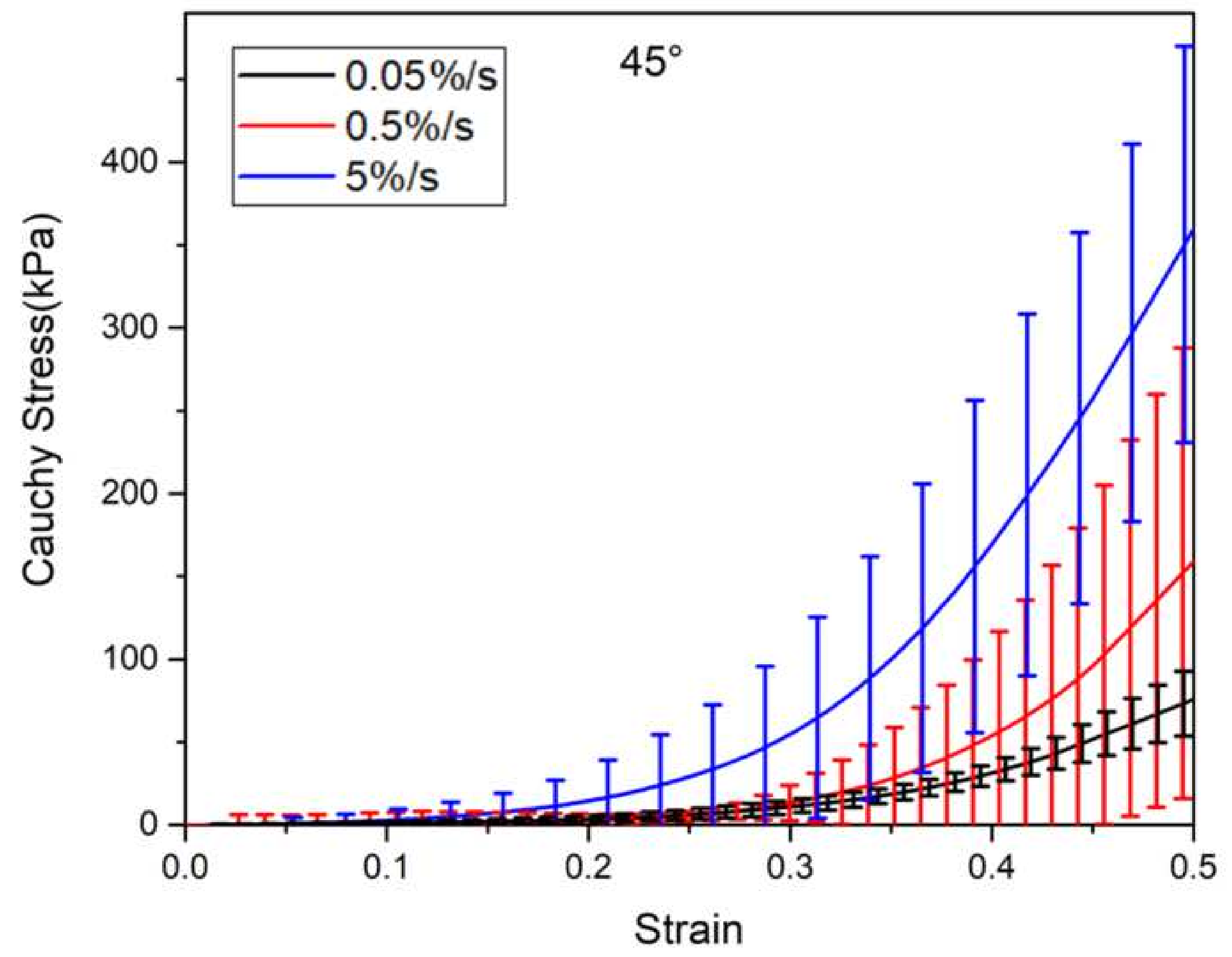


Click here to access/download;Figure;Figure.4(c).png $\underline{\underline{ \pm}}$

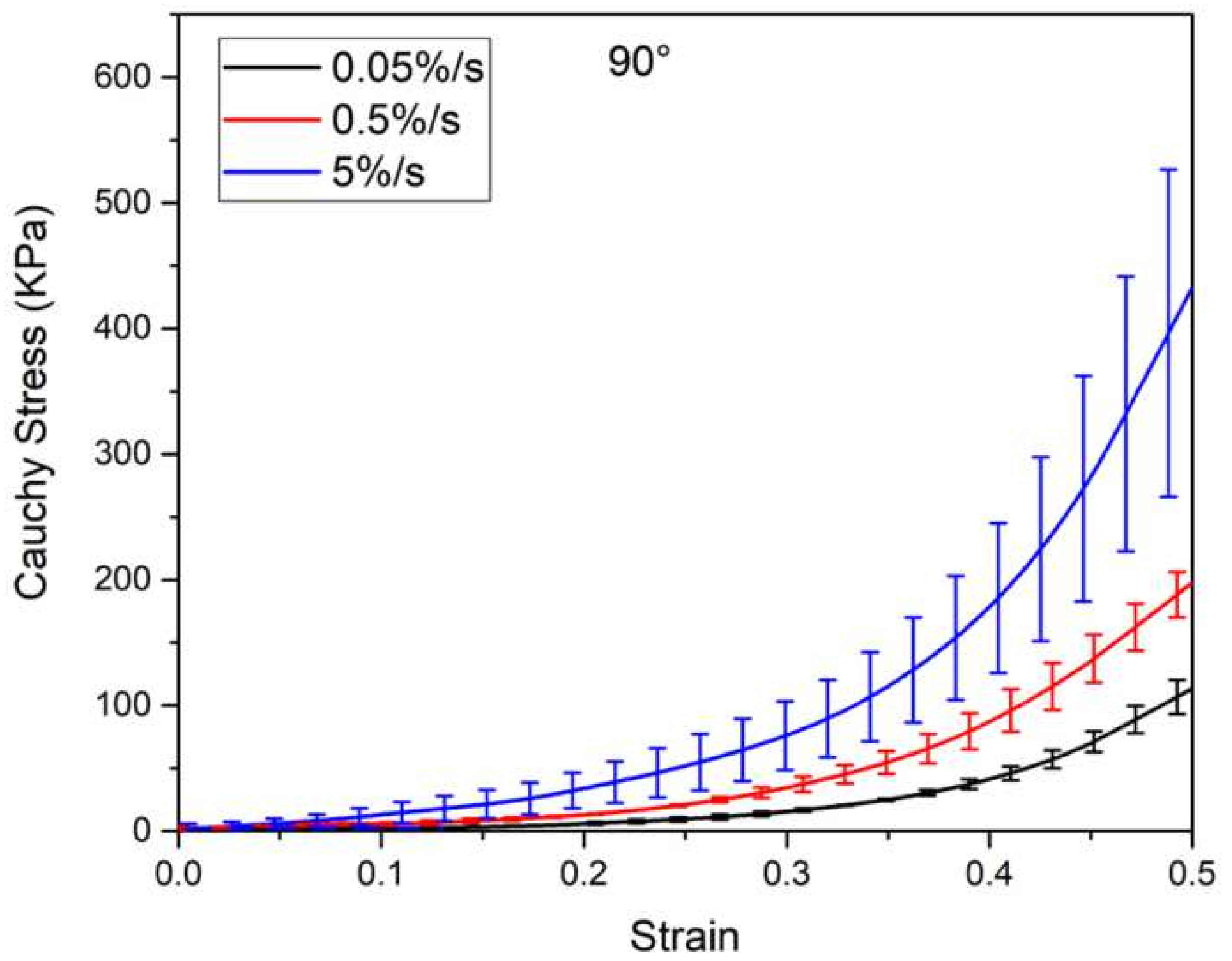




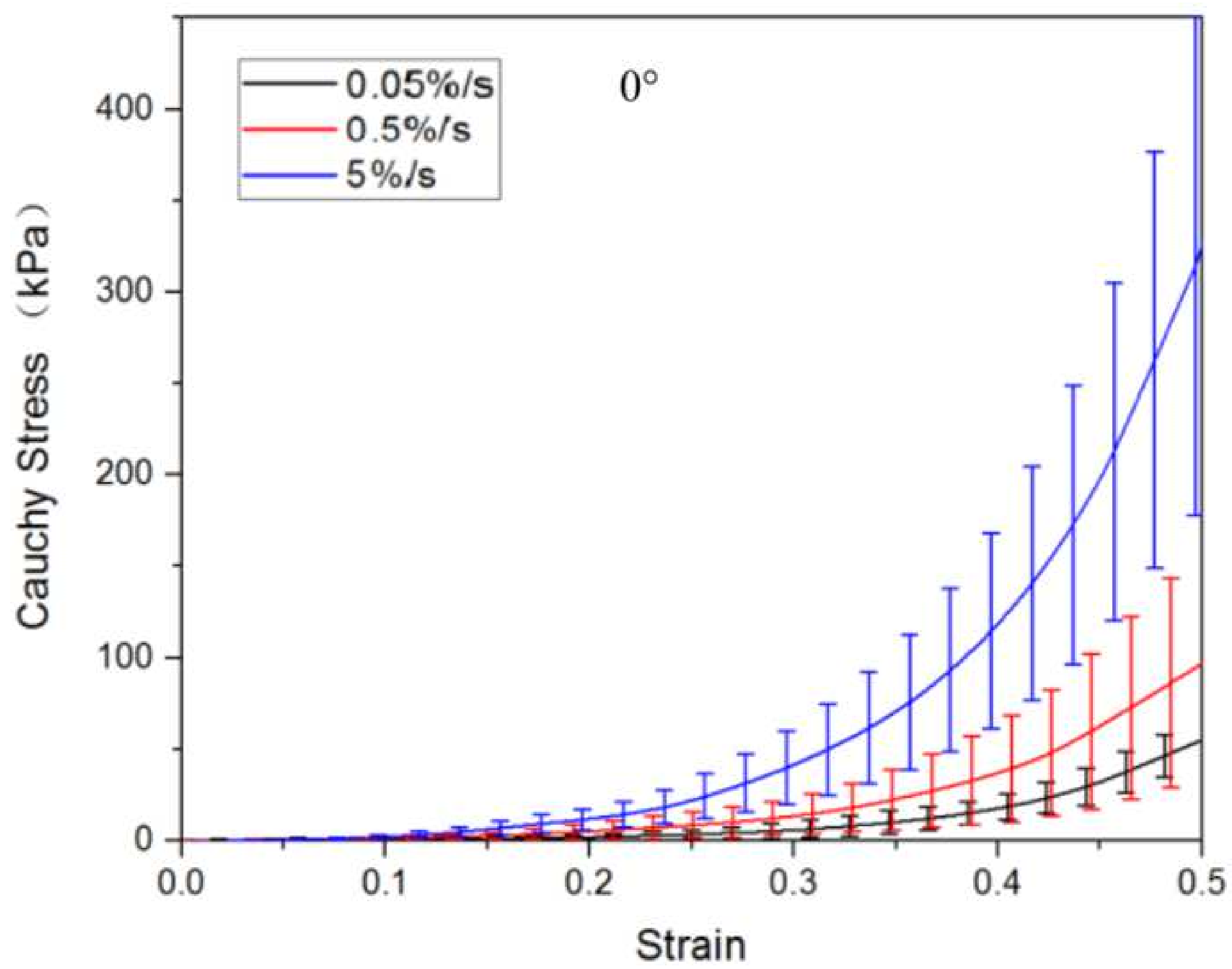




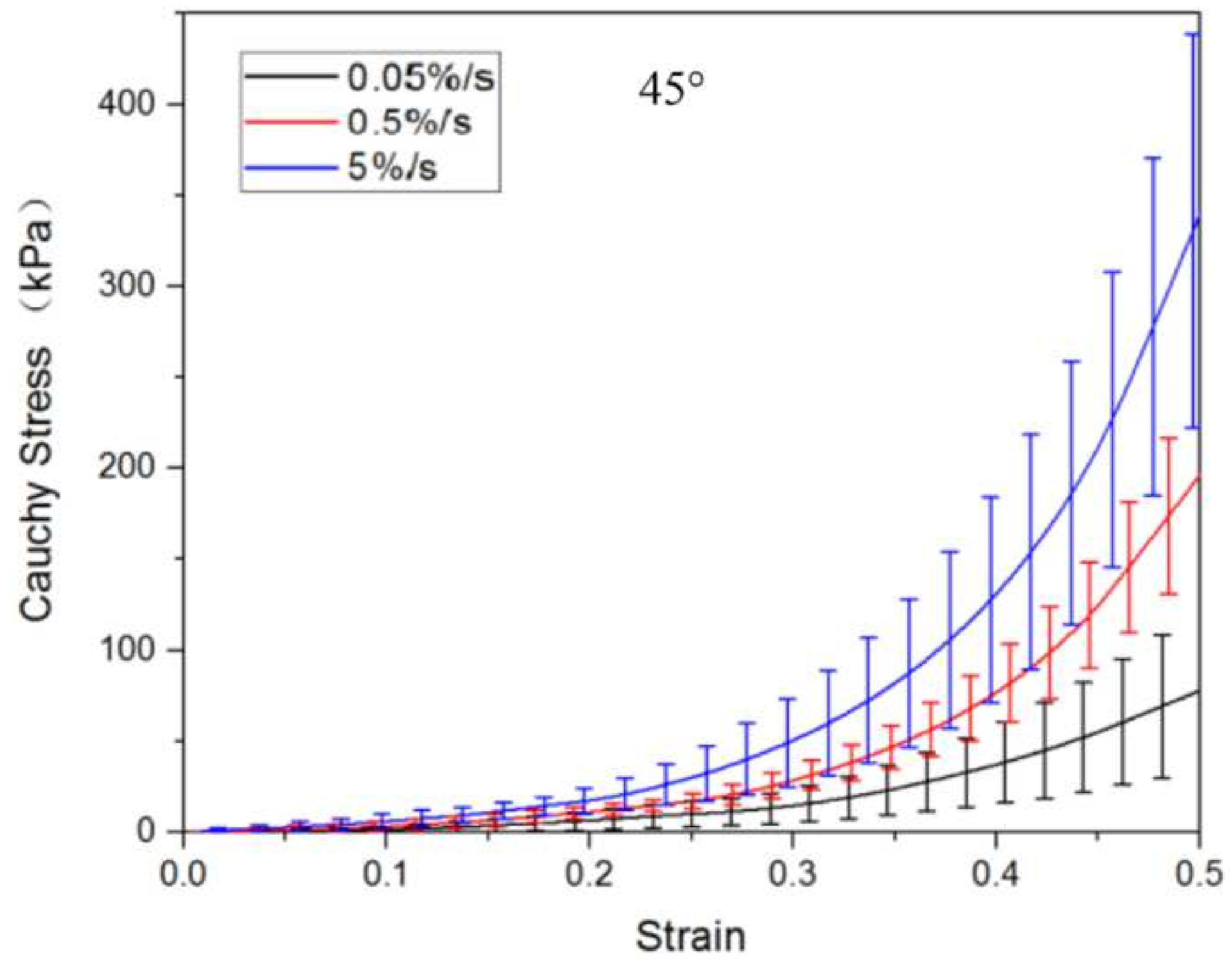




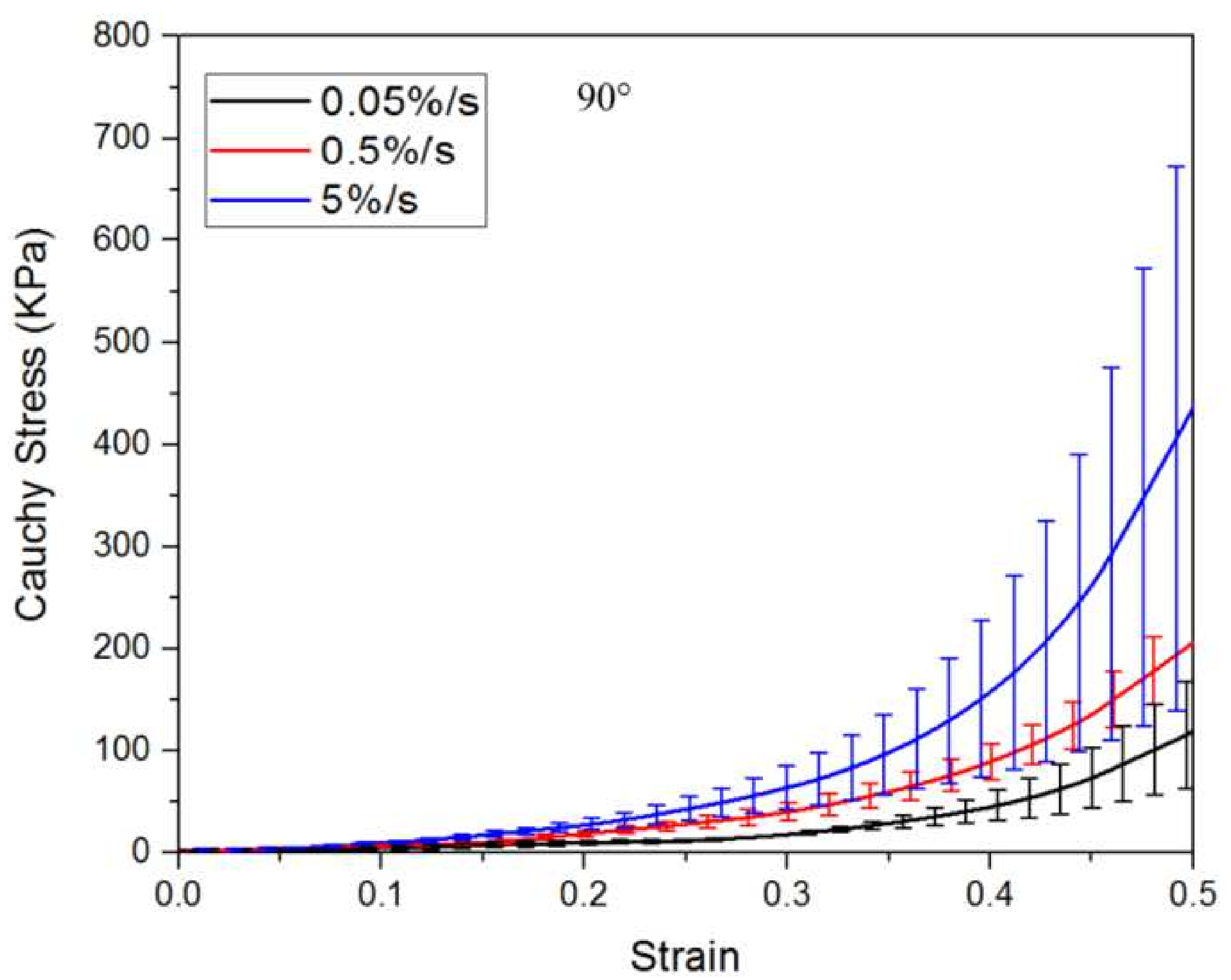




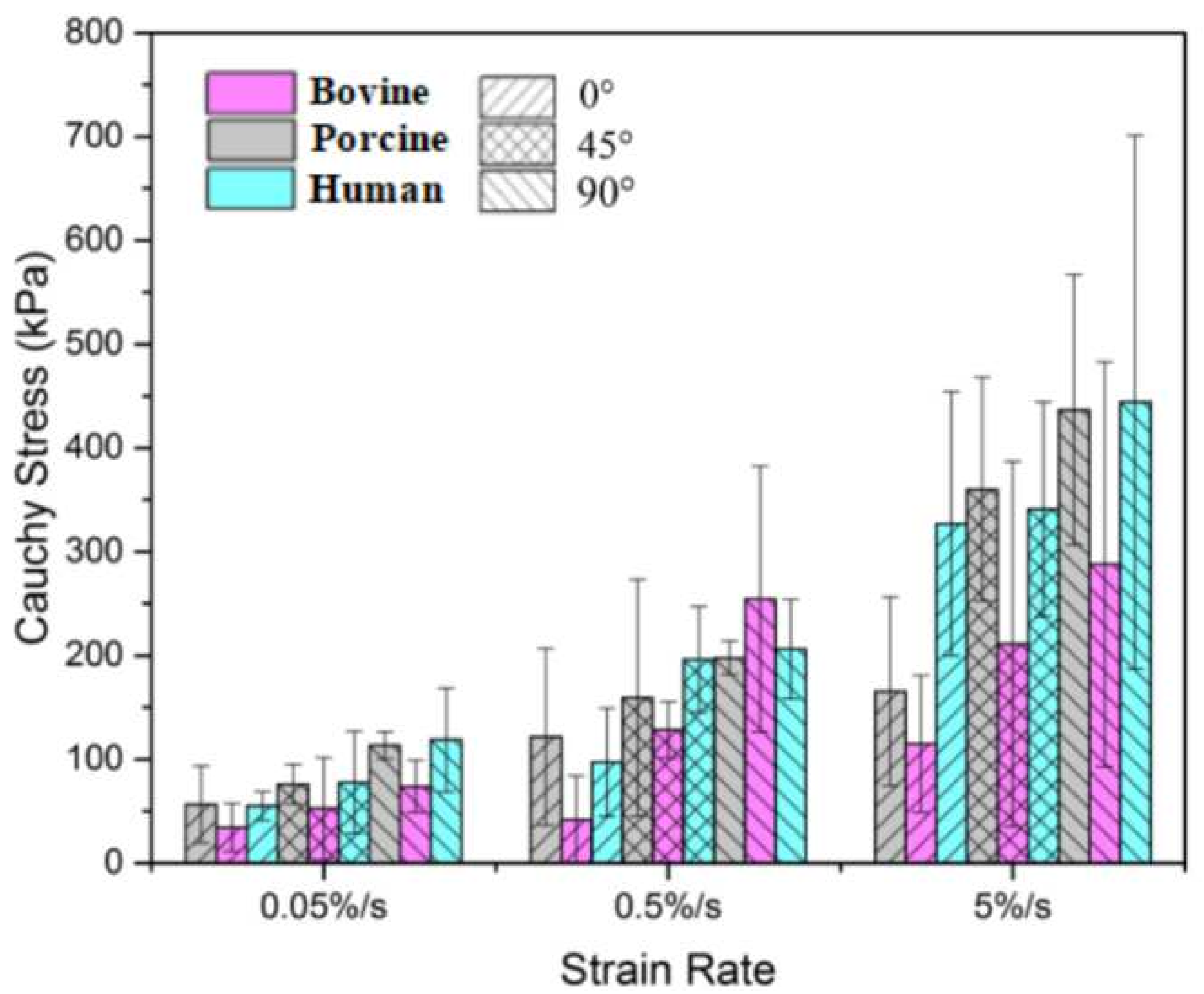




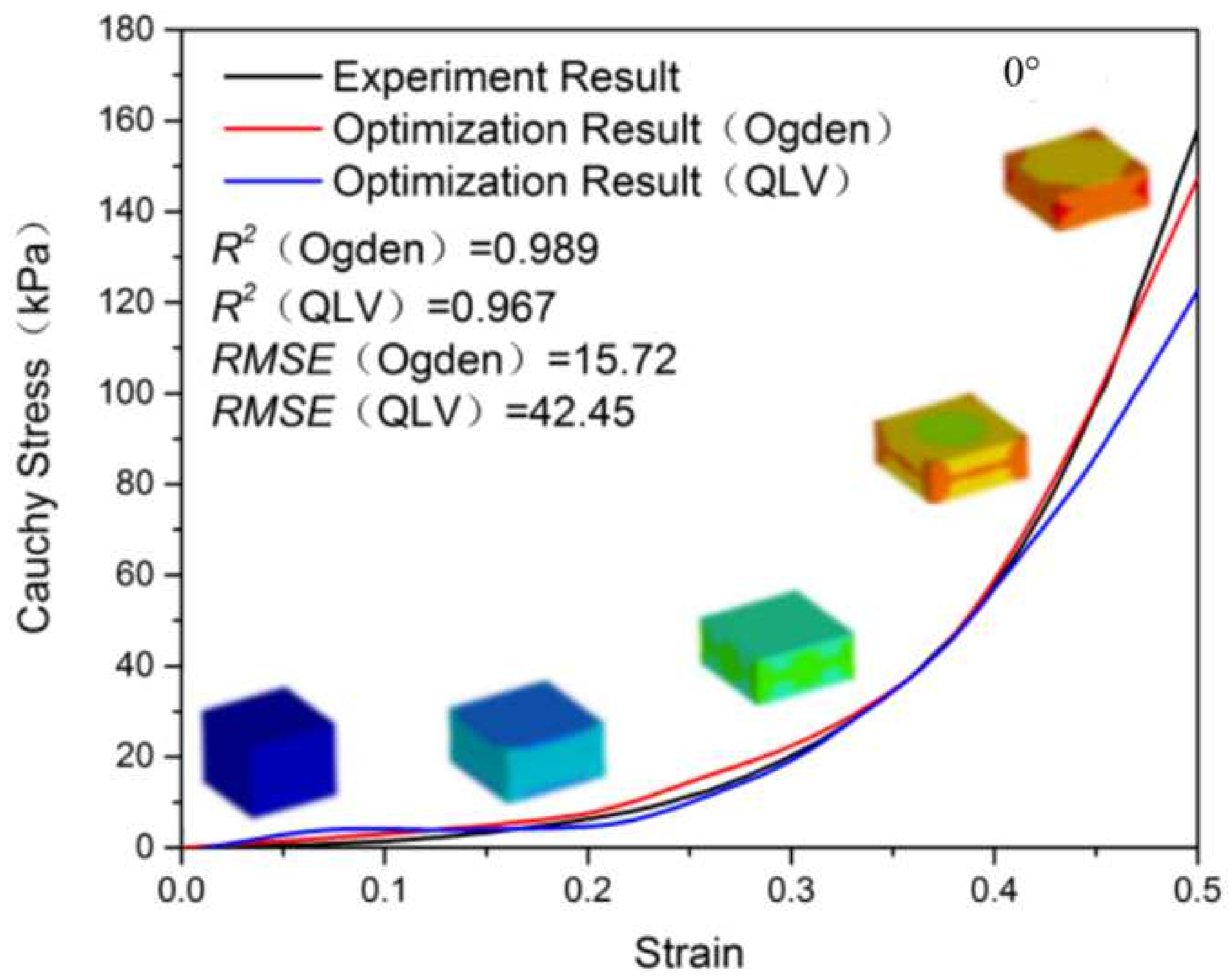




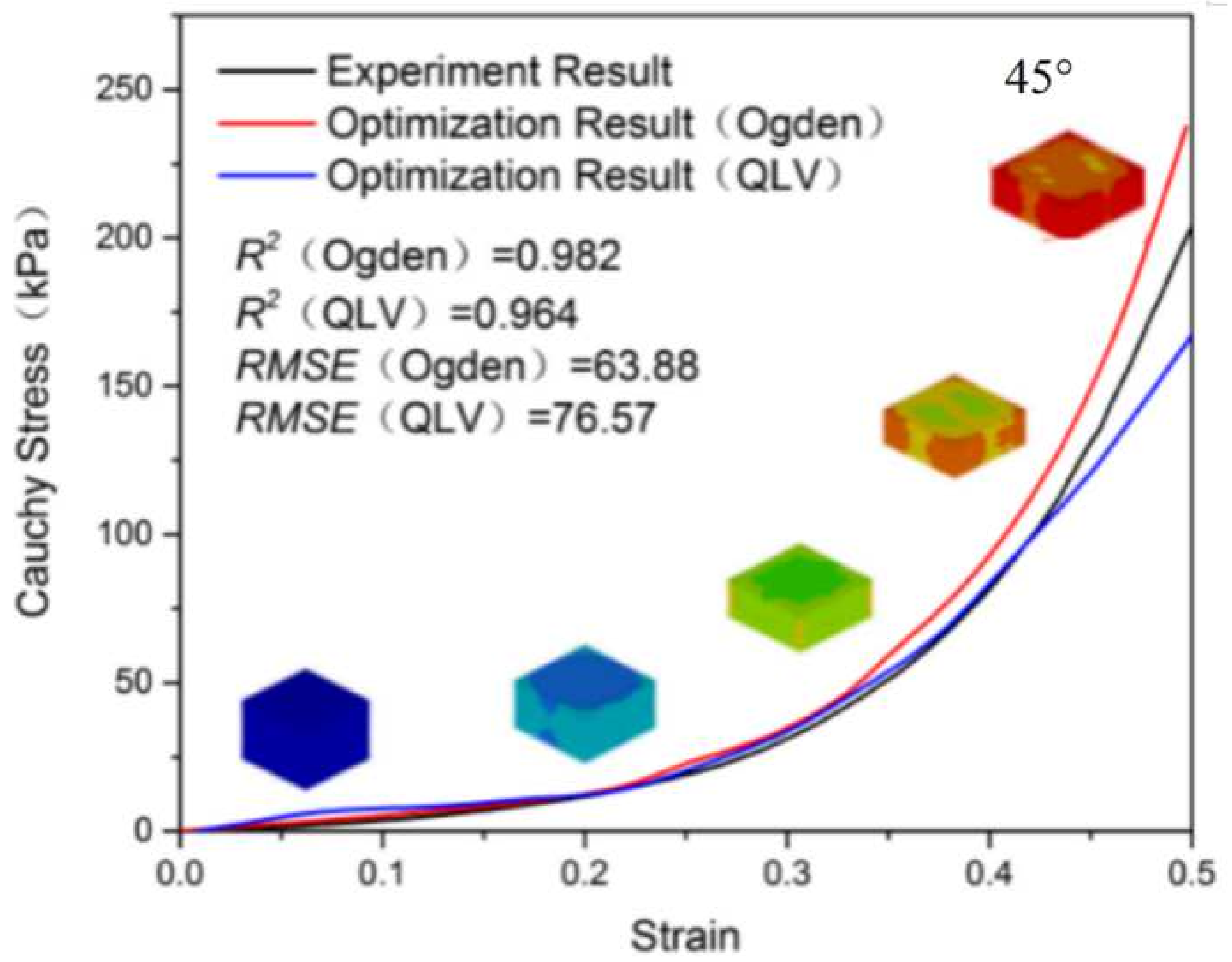




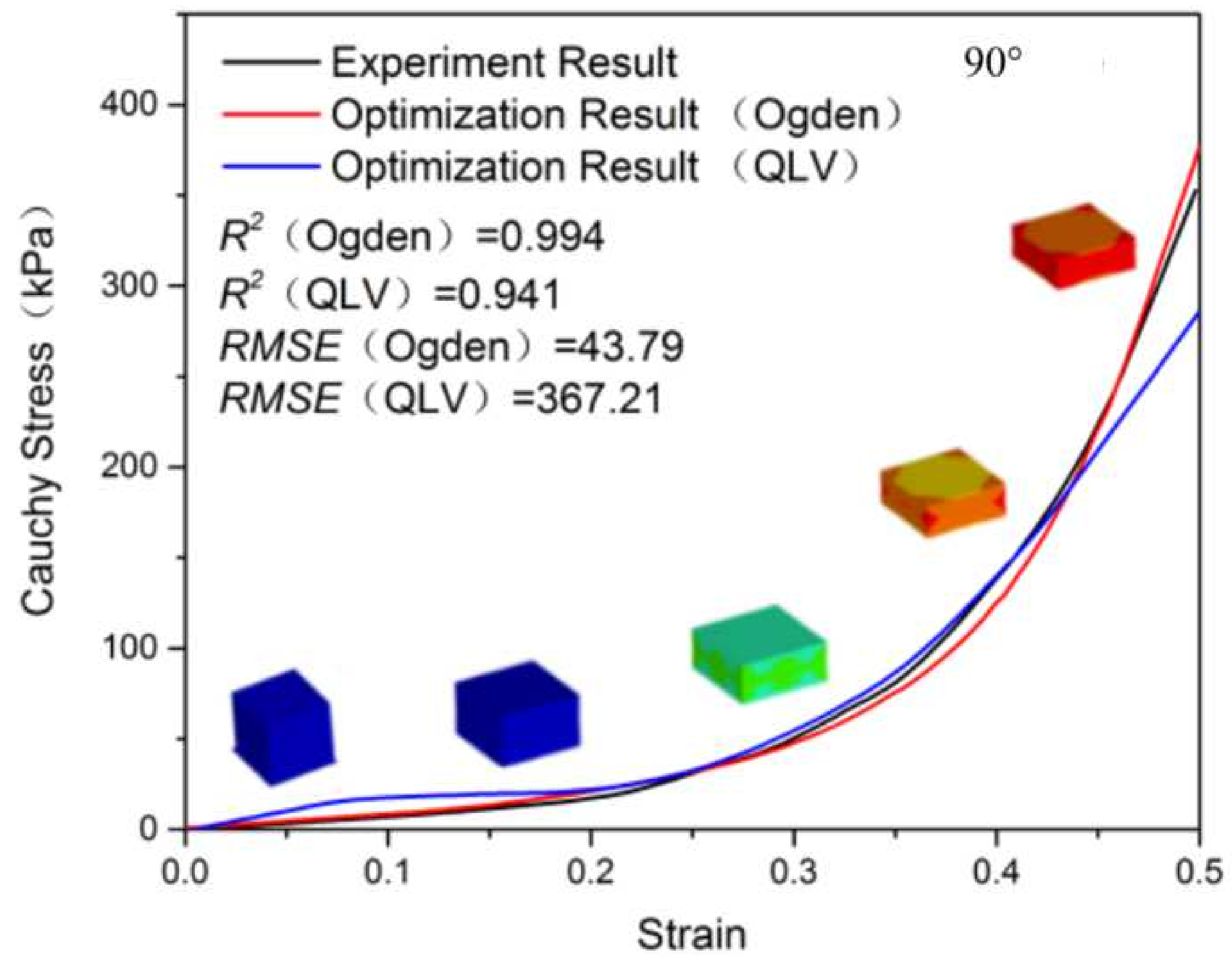




\section{Conflict of Interest Statement}

Fuhao MO, Zhefen ZHENG, Haotian ZHANG, Guibing LI, Zurong YANG, Deyi Sun, J Biomechanics

Title: In vitro compressive properties of skeletal muscles and inverse finite element analysis: comparison of human versus animals

The authors assert that there are no conflicts of interest of any type.

This assertion is also included in the manuscript. 
Fuhao MO: Conceptualization, Methodology, Writing- Reviewing and Editing, Supervision; Zhefeng ZHENG: Data curation, Formal analysis, Writing- Original draft preparation; Haotian ZHANG, Software, Validation;

Guibing Li: Investigation, Visulization;

ZuRong YANG: Validation;

Deyi Sun: Resources, Writing- Reviewing and Editing, Supervision. 